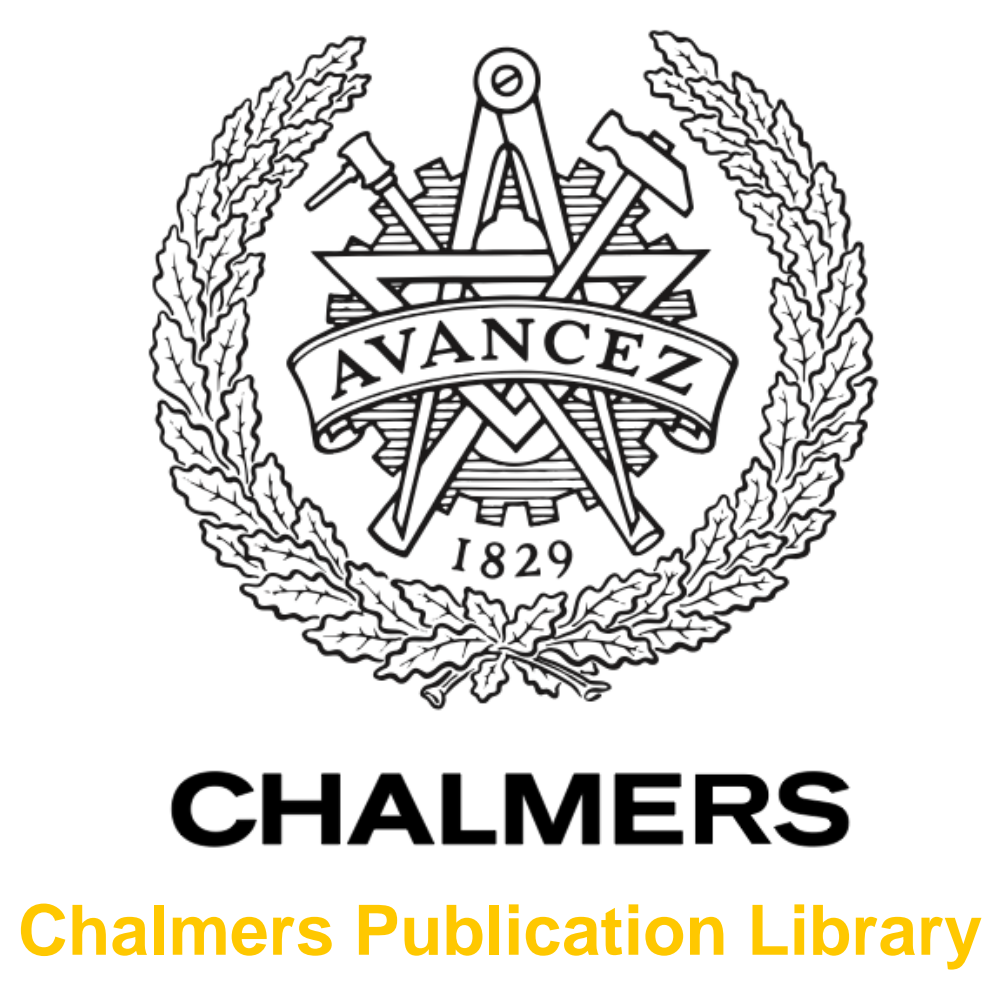

\title{
Implementation of failure criteria for transverse failure of orthotropic Non-Crimp Fabric composite materials
}

This document has been downloaded from Chalmers Publication Library (CPL). It is the author's version of a work that was accepted for publication in:

Composites. Part A, Applied science and manufacturing (ISSN: 1359-835X)

Citation for the published paper:

Molker, H. ; Renaud, G. ; Asp, L. (2016) "Implementation of failure criteria for transverse failure of orthotropic Non-Crimp Fabric composite materials". Composites. Part A, Applied science and manufacturing

http://dx.doi.org/10.1016/j.compositesa.2016.09.02

1

Down「oaded from: http://publications.lib.chalmers.se/publication/242793

Notice: Changes introduced as a result of publishing processes such as copy-editing and formatting may not be reflected in this document. For a definitive version of this work, please refer to the published source. Please note that access to the published version might require a subscription. 


\title{
Implementation of failure criteria for transverse failure of orthotropic Non-Crimp Fabric composite materials
}

\author{
Henrik Molker ${ }^{a, b, *}$, Renaud Gutkin ${ }^{\mathrm{c}}$, Leif E. Asp ${ }^{\mathrm{b}}$ \\ ${ }^{a}$ Durability CAE Body \& Trim, Volvo Car Corporation, 40531 Gothenburg, Sweden \\ ${ }^{\mathrm{b}}$ Department of Applied Mechanics, Chalmers University of Technology, 41296 Gothenburg, Sweden \\ ${ }^{\mathrm{c}}$ Swerea SICOMP AB, Box 104, 43122 Mölndal, Sweden
}

\begin{abstract}
In this paper a set of failure criteria for Non-Crimp Fabric (NCF) reinforced composites is implemented in a Finite Element (FE) software. The criteria, implemented at the ply level, predict transverse failure of NCF reinforced composites, in particular accounting for their inherent orthotropic properties. Numerical simulations are compared with tests on specimens with a generic design feature found in automotive structures. The current implementation enables correct prediction of failure mode and location.
\end{abstract}

Keywords: Carbon fibres ; Strength ; Finite element analysis (FEA) ; Failure

\section{Introduction}

The present research is part of a bigger effort aiming at identifying and further developing industrially efficient, yet scientifically based, Computer Aided Engineering (CAE) methods for vehicle structures made of high performance Carbon Fibre Reinforced Polymers (CFRP). CFRP automotive bodies today can be 50\% lighter compared to corresponding steel alternatives and 30\% lighter than aluminium alternatives with similar or improved stiffness, durability and crash worthiness 
properties. CFRP structures are therefore an outstanding alternative for lowering the weight of load carrying structures needed to meet future requirements on emissions and energy consumption.

Amongst the different types of composite materials available, Non-Crimp Fabric (NCF) reinforced composites manufactured by Resin Transfer Moulding (RTM) [1,2] are strong candidates for the automotive industry. NCF reinforced composite materials are orthotropic [3] in contrast to traditional transversely isotropic Uni-Directional (UD) fibre composites. In particular, uni-weave NCF reinforced composites have been found to have significantly lower out-of-plane strength compared to the transverse in-plane strength $[4,5]^{1}$. In tension in the out-of-plane direction, this is explained by the interbundle failure mode occurring at the interface between the fibre bundle and surrounding matrix $[4,6]$. Established physically based failure criteria developed for UD composites $[7,8]$ do not take this orthotropic behaviour into account.

When composite structures are designed it is desirable to avoid out-of-plane loading conditions, or use guidelines to minimize the risk of out-of-plane loading [7]. However, avoiding this will not be possible within the automotive industry where many features and details are incorporated in the structures that are subjected to complex load cases. Being able to accurately predict failure initiation then becomes even more important when using materials with orthotropic properties, whose out-of-plane strength is lower than the transverse in-plane strength.

\footnotetext{
${ }^{1}$ The authors are not aware of any studies on multi-axial NCF reinforced composites to show if the low out-of-plane tensile strength is general to all NCF reinforced composites or limited to uni-weaves.
} 
Current state of the art physically based failure criteria, e.g. Puck [8] and LaRC05 [9], assume transverse isotropy and cannot capture the orthotropic nature of transverse failure observed for NCF composites [4,6]. Consequently, to allow the use of NCF composites in automotive applications, failure criteria accurately predicting failure initiation under general 3D stress states were proposed and compared with other failure criteria by Molker et al. [6].

This paper presents the implementation of a set of physically based failure criteria for transverse failure initiation in NCF reinforced composites, taking the orthotropic nature into account. The implementation is done in the commercial FE code Abaqus/Standard. The criteria have been developed in a previous work [6] and are based on the LaRC05 criteria [9], adapted to address the orthotropic properties with an additional failure mode. Assessment of the numerical approach is performed by comparison to test data from specimens with a generic design feature that can be found in real automotive applications.

\section{Failure of NCF reinforced composites}

$\mathrm{NCF}$ reinforced composites are not transversely isotropic as UD reinforced composites. Failure initiation criteria developed for UD reinforced composites cannot therefore be used to predict failure initiation in NCFs. A set of criteria presented by Molker et al. [6] addresses this for transverse failure by introducing an additional failure mode for transverse out-of-plane failure initiation. 
The new failure criterion for out-of-plane transverse failure is added to the LaRC05 set of criteria [9] for initiation of transverse failure. LaRC05 has been chosen as it is physically based and its predictive capability has been verified in the World Wide Failure Exercise [10]. The material properties needed can be found from standard material tests. The additional criterion for out-of-plane transverse failure could also be used together with other criteria for UD reinforced composites, e.g. Puck [8], LaRC04 [11] or the criteria proposed by Catalanotti et al. [12], which address some additional aspects of failure initiation.

Interbundle failure has been found to initiate at the outer region of a fibre bundle propagating to the matrix surrounding the fibre bundles. Therefore, it is treated as a failure mode inside the composite material and not as delamination between plies of NCF reinforcements. However, it is noted that the criterion for the interbundle failure mode uses a polynomial stress based approach similar to Ye's delamination onset criterion [13].

The present article focuses on the implementation of the proposed set of criteria for transverse failure of NCF reinforced composites [6]. Comparisons to other failure criteria were made in Ref. [6] against a criterion for NCF reinforced materials proposed in the literature $[14,15]$ and a meso-mechanical FE model, with good agreement. 


\subsection{Failure criteria for NCF reinforced composites considering two modes of transverse failure}

NCF reinforced composites can be evaluated, taking the orthotropic strength and different failure modes into account, by introducing the failure criteria presented previously by Molker et al. [6]. In these criteria, an additional mode is introduced for transverse matrix related failure to complement the LaRC05 matrix failure criterion.

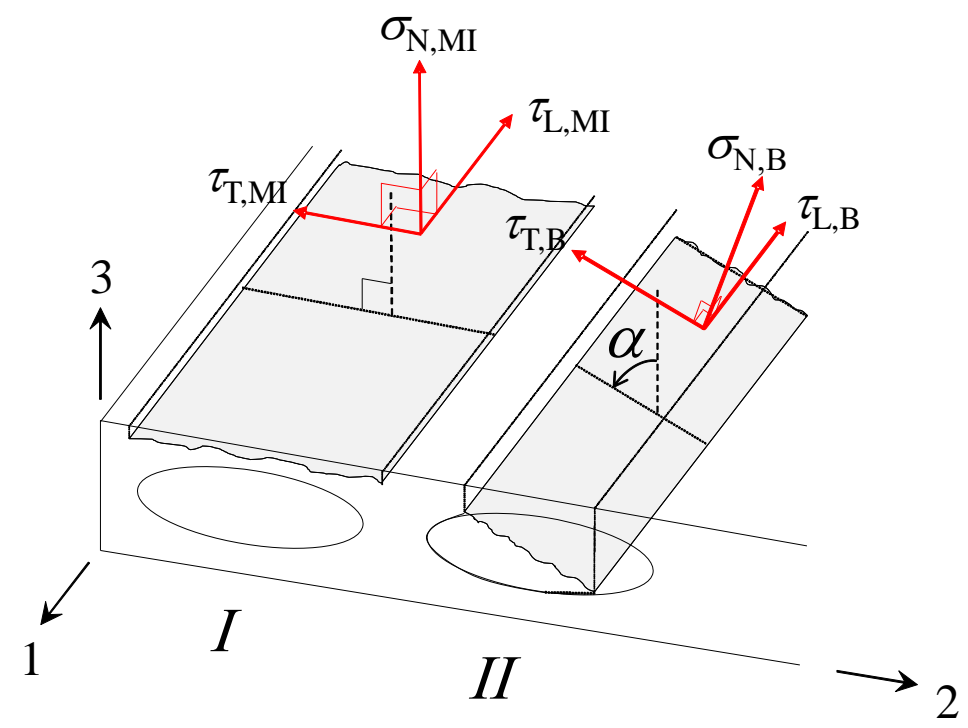

Figure 1. Transverse fracture planes within a NCF lamina. Transverse interbundle failure at Bundle I, with a fracture plane perpendicular to the thickness direction. Transverse intrabundle failure at Bundle II, with a fracture plane at an angle $\alpha$ inside the fibre bundle.

The additional transverse failure mode, denoted as transverse interbundle failure, is observed for out-of-plane tensile loading, at the interface between the impregnated fibre bundle and the surrounding matrix [6]. The fracture plane is perpendicular to the thickness direction, as illustrated for Bundle I in Figure 1. The strength for this mode is significantly lower compared to the transverse intrabundle failure mode, shown in Figure 1, Bundle II. The transverse interbundle failure mode in NCF reinforced composites is evaluated on a fracture plane perpendicular to the thickness direction. The failure initiation is evaluated using a failure criterion based on the traction acting at the 
Matrix Interface (MI), using the shear strengths $S_{\mathrm{T}, \mathrm{MI}}$ and $S_{\mathrm{L}, \mathrm{MI}}$ and out-of-plane strength $Z_{\mathrm{T}}$. This failure index is denoted $F I_{\mathrm{M}, \mathrm{MI}}$.

$$
F I_{\mathrm{M}, \mathrm{MI}}=\left(\frac{\tau_{\mathrm{T}, \mathrm{MI}}}{S_{\mathrm{T}, \mathrm{MI}}}\right)^{2}+\left(\frac{\tau_{\mathrm{L}, \mathrm{MI}}}{S_{\mathrm{L}, \mathrm{MI}}}\right)^{2}+\left(\frac{\sigma_{\mathrm{N}, \mathrm{MI}}}{Z_{\mathrm{T}}}\right)^{2}=1 \text {, if } \sigma_{\mathrm{N}, \mathrm{MI}}>0 .
$$

Interbundle failure initiation is only computed, using Eq. (1), if the out-of-plane normal stress is positive. Therefore, if a high level of out-of-plane shear stress combined with low out-of-plane compressive stress is applied to the material the model assumes that no interbundle failure can occur. This assumption has been made as no experimental results are available for such load cases. In Eq. (1), for convenience the shear strength $S_{\mathrm{T}, \mathrm{MI}}$ and $S_{\mathrm{L}, \mathrm{MI}}$ are assumed equal to the interlaminar shear strength (ILSS), as this failure occurs within the matrix material,

$$
S_{\mathrm{T}, \mathrm{MI}}=S_{\mathrm{L}, \mathrm{MI}}=I L S S \text {. }
$$

The transverse intrabundle failure mode is evaluated using the LaRC05 criterion for matrix failure [9], denoted $F I_{\mathrm{M}, \mathrm{B}}$, and including in-situ effects, denoted by superscript is [9].

$$
F I_{\mathrm{M}, \mathrm{B}}=\left(\frac{\tau_{\mathrm{T}, \mathrm{B}}}{S_{\mathrm{T}}^{i s}-\eta_{\mathrm{T}} \sigma_{\mathrm{N}, \mathrm{B}}}\right)^{2}+\left(\frac{\tau_{\mathrm{L}, \mathrm{B}}}{S_{\mathrm{L}}^{i s}-\eta_{\mathrm{L}} \sigma_{\mathrm{N}, \mathrm{B}}}\right)^{2}+\left(\frac{\left\langle\sigma_{\mathrm{N}, \mathrm{B}}\right\rangle_{+}}{Y_{\mathrm{T}}^{i s}}\right)^{2}=1
$$

where the transverse shear strength $S_{\mathrm{T}}$ is based on the transverse compressive strength $Y_{\mathrm{C}}$ as:

$$
S_{\mathrm{T}}=Y_{\mathrm{C}} \cos \left(\alpha_{0}\right)\left(\sin \left(\alpha_{0}\right)+\frac{\cos \left(\alpha_{0}\right)}{\tan \left(2 \alpha_{0}\right)}\right)
$$

and where the friction parameters $\eta_{\mathrm{T}}$ and $\eta_{\mathrm{L}}$ are related to the shear strengths $S_{\mathrm{L}}$ and $S_{\mathrm{T}}$ as: 


$$
\frac{\eta_{\mathrm{T}}}{S_{\mathrm{T}}}=\frac{\eta_{\mathrm{L}}}{S_{\mathrm{L}}}
$$

and $Y_{\mathrm{T}}$ denotes the in-plane tensile strength and $S_{\mathrm{L}}$ the longitudinal shear strength. Insitu values for the strength parameters, $S_{\mathrm{T}}, S_{\mathrm{L}}$ and $Y_{\mathrm{T}}$, are calculated according to Ref. [9].

The transverse failure index $F I_{\mathrm{M}}$ is evaluated as the highest of $F I_{\mathrm{M}, \mathrm{MI}}$ and $F I_{\mathrm{M}, \mathrm{B}}$ for all potential fracture planes (with angle $\alpha$ ) for the current stress state.

$$
F I_{\mathrm{M}}=\max \left(F I_{\mathrm{M}, \mathrm{MI}}, \max _{\alpha=\left[0^{\circ}, 180^{[}\right.}\left(F I_{\mathrm{M}, \mathrm{B}}\right)\right)
$$

\subsection{Implementation in finite element software}

Failure can initiate in any direction within the material and is determined by the current 3D stress state. Therefore, solid elements were used. Cohesive elements could have been used to trigger the interbundle failure as this occurs on a fracture plane perpendicular to the thickness direction. However, as only initiation is considered in the present work, this would create a more complex model that would increase the computational cost and the model preparation time.

The proposed failure criteria are implemented in Abaqus/Standard [16] using a user defined subroutine UVARM [16], which is used to create element output variables at each integration point and each time increment. The criteria use the full stress tensor to calculate the tractions on the potential fracture planes.

For all elements, the current 3D stress state is retrieved and the resolved tractions on potential fracture planes $\left(\alpha \mathrm{M}, \mathrm{MI}=90^{\circ}\right.$ and $\alpha \mathrm{M}, \mathrm{B}=\left[0^{\circ}, 180^{\circ}[)\right.$ are calculated as shown in Figure 1. The failure indices according to Eq. (1) and Eq. (3) are then calculated and the 
most critical mode is determined according to Eq. (6). The corresponding failure index, failure mode and fracture plane angle are extracted and defined as output quantities.

For comparison with traditional state of the art criteria for transversely isotropic material, transverse matrix failure according to LaRC05 is also calculated and outputted for the current stress state. This is equal to the transverse intrabundle failure mode, $F I_{\mathrm{M}, \mathrm{B}}$, i.e. Eq. (3).

\section{Comparison with test on a generic design feature}

To verify the implementation in Abaqus, numerical simulations have been performed on a simplified structure but with a generic design feature typical of automotive structures. The specimen was loaded to achieve a 3D stress state and the numerical results were compared with the experimental data. Two different stacking sequences, $[90]_{16}$ and $[90 / 0]_{4 s}$, were chosen to trigger either the interbundle or the intrabundle failure modes. Specimens, with identical geometry, were manufactured and tested for the two lay-ups. The specimens were loaded in a test rig according to the analysed load case.

\subsection{Material}

The material used was a uni-weave of HTS45 fibres (Porcher, $205 \mathrm{~g} / \mathrm{m}^{2}$ ) and LY556 (Huntsman) matrix. Elastic properties and strength properties, together with data needed for in-situ strength calculations, are given in Table 1 and Table 2, respectively [5]. The specimens were hand laid in a mould and processed by vacuum assisted resin transfer moulding. 
The specimens were infused in a preheated tool at $40^{\circ} \mathrm{C}$ and with the resin preheated at $40^{\circ} \mathrm{C}$. The infusion took place at 98 mbar for 45 minutes after which also the pressure was increased to 650 mbar for 20 minutes before the inlet was closed. The specimens were cured for 6 hours at $80^{\circ} \mathrm{C}$ and post-cured for 4 hours at $80{ }^{\circ} \mathrm{C}$ and another 4 hours at $140{ }^{\circ} \mathrm{C}$.

\begin{tabular}{ccccccccc}
\hline $\begin{array}{c}E_{11} \\
(\mathrm{GPa})\end{array}$ & $\begin{array}{c}E_{22} \\
(\mathrm{GPa})\end{array}$ & $\begin{array}{c}E_{33} \\
(\mathrm{GPa})\end{array}$ & $v_{12}$ & $v_{13}$ & $v_{23}$ & $\begin{array}{c}G_{12} \\
(\mathrm{GPa})\end{array}$ & $\begin{array}{c}G_{13} \\
\mathrm{GPa})\end{array}$ & $\begin{array}{c}G_{23} \\
(\mathrm{GPa})\end{array}$ \\
\hline $\begin{array}{c}136.0 \\
\text { a) }\end{array}$ & $9.2^{\mathrm{a})}$ & $8.0^{\mathrm{a})}$ & 0.29 & 0.29 & 0.43 & 4.3 & 3.7 & 2.8 \\
& \\
&
\end{tabular}

Table 1: Elastic properties of the NCF reinforced composite at the homogenised ply level [5].

\begin{tabular}{|c|c|c|c|c|c|c|}
\hline $\begin{array}{c}Y_{\mathrm{T}} \\
(\mathrm{MPa}) \\
\end{array}$ & $\begin{array}{c}Y_{\mathrm{C}} \\
(\mathrm{MPa}) \\
\end{array}$ & $\begin{array}{c}Z_{\mathrm{T}} \\
(\mathrm{MPa})\end{array}$ & $\begin{array}{c}Z_{\mathrm{C}} \\
(\mathrm{MPa}) \\
\end{array}$ & $\begin{array}{c}S_{\mathrm{L}} \\
(\mathrm{MPa}) \\
\end{array}$ & $\begin{array}{c}\alpha_{0} \\
(\mathrm{deg})\end{array}$ & $\begin{array}{r}I L S S \\
(\mathrm{MPa}) \\
\end{array}$ \\
\hline 29 & 130 & 15 & 202 & 78 & 62 & 42 \\
\hline $\begin{array}{c}G_{\mathrm{IC}} \\
\left(\mathrm{J} / \mathrm{m}^{2}\right.\end{array}$ & $\begin{array}{c}G_{\mathrm{IIC}} \\
\left(\mathrm{J} / \mathrm{m}^{2}\right)\end{array}$ & & & $\begin{array}{l}Y_{\mathrm{T}}^{\text {is }} \\
\mathrm{MPa})\end{array}$ & $\begin{array}{c}S_{\mathrm{L}}^{\text {is }} \\
(\mathrm{MPa})\end{array}$ & $\begin{array}{c}S_{\mathrm{T}}^{\text {is }} \\
(\mathrm{MPa})\end{array}$ \\
\hline 149 & 690 & & & 6 & 94 & 49 \\
\hline
\end{tabular}

Table 2: Strength properties of the NCF reinforced composite at the homogenised ply level [5]. Both the measured laminae data, used for the [90 $]_{16}$ layup, and the calculated in-situ values for the $[90 / 0]_{4 \mathrm{~S}}$ layup are listed.

For the [90 $]_{16}$ lay-up the $Y_{\mathrm{T}}, S_{\mathrm{L}}$ and $S_{\mathrm{T}}$ values are used. For the [90/0 $]_{4 \mathrm{~S}}$ lay-up the insitu strengths, $Y_{\mathrm{T}}{ }^{\text {is }}, S_{\mathrm{L}}{ }^{\text {is }}$ and $S_{\mathrm{T}}$ is , for transverse matrix cracking are calculated according to Ref. [9], with a ply thickness of $0.1875 \mathrm{~mm}$, and accounting for the non-linear response in in-plane shear. The value of $\beta$, that defines the non-linearity of the shear stress-strain relation, has been obtained according to Ref. [17].

\subsection{Geometry}

The geometry used is a corrugated panel described in Ref. [18]. For the coupons, a $20 \mathrm{~mm}$ long section of the plate is used consisting of one crest and two bays, with a radius of $9.5 \mathrm{~mm}$ and approximately $40 \mathrm{~mm}$ wide, see Figure 2 (a). The length was 
determined using FE analysis to achieve a homogeneous stress distribution along the length of the specimen.

(a)

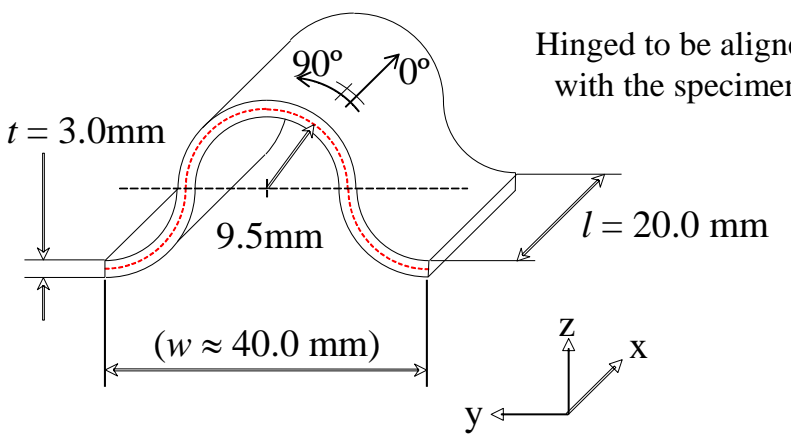

(b)

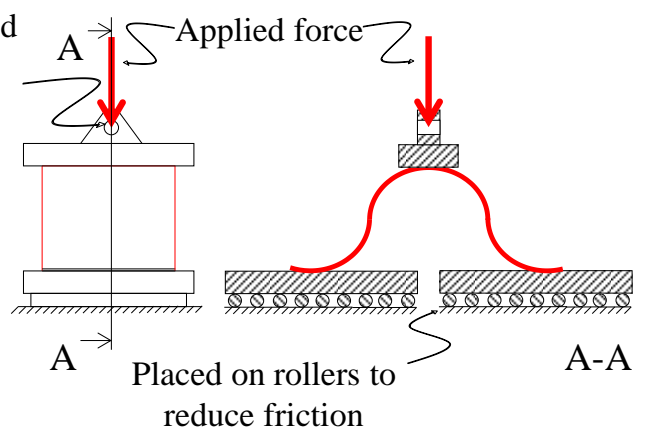

Figure 2. (a) Geometry of test specimen. (b) Loading and boundary conditions of the specimen. Side view along the length of the specimen and along cross-section A-A.

\subsection{Load case}

The load case was designed to achieve a moment over the specimen that will open the radius, see Figure 2 (b), thereby creating interlaminar tensile stresses within the specimen, similar to the ones in Ref. [19]. The lay-ups are chosen to obtain the interbundle failure mode before intrabundle failure of the inner plies due to transverse matrix failure.

\subsection{Experimental setup}

The coupons were placed on two rolling beds to minimise the friction while only constraining the movement in the load direction and allowing free sliding in the widthdirection of the specimen, as illustrated in Figure 2 (b). The specimens were mechanically loaded in a Zwick universal testing machine with a $10 \mathrm{kN}$ load cell. The experiments were performed under displacement control with a loading rate of $0.01 \mathrm{~mm} / \mathrm{s}$ to avoid any dynamic effects. 
For all specimens the load versus displacement was recorded together with images from a Dino-Lite Premier USB microscope (AD7013MTL). Crack growth is unstable for the current specimen and loading configuration, therefore only a fully developed crack could be observed upon damage initiation.

Five coupons of each lay-up were tested. Three were tested beyond failure initiation to verify that they all showed the same response and similar failure sequence. Two specimens were tested up to initiation, which was determined as the first major load drop, and was also identified by the first sound emitted and the first visible damage from the microscope.

\subsection{Numerical simulations}

The numerical simulations were performed using the implicit FE code Abaqus/Standard. The analyses are done on the assumption that the materials are elastic orthotropic. The specimen is modelled with 48,000 solid second order hexahedral elements with one element over the thickness of each NCF ply, see Figure 3. A biasing of the elements is done to increase the mesh density in the critical upper half. The average element size is $0.19 \times 0.50 \times 0.66 \mathrm{~mm}$ in the radial (ply thickness), tangential and length directions, respectively. 


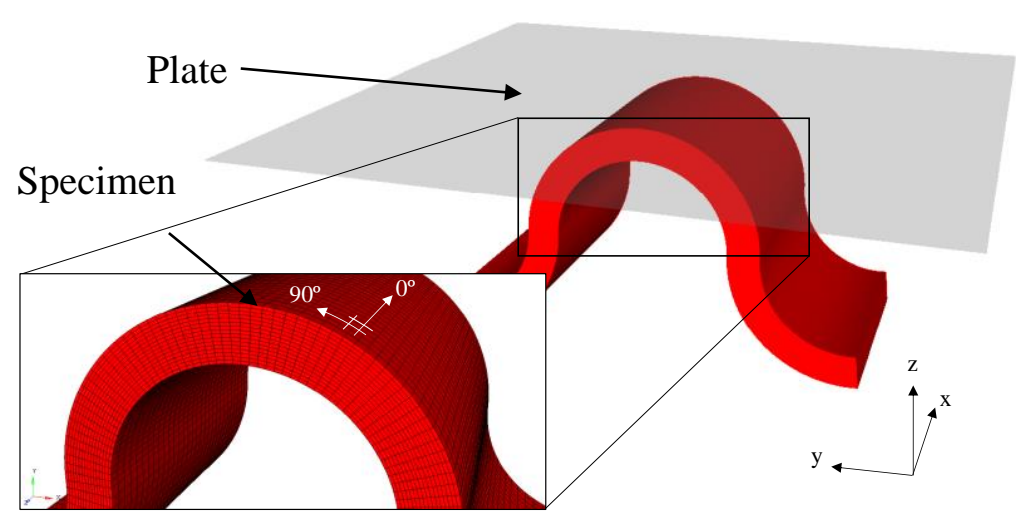

Figure 3. Illustration of the FE model with rigid surface on top. Close up at the upper part of the mesh.

The loading is achieved through a prescribed displacement of a rigid surface which contacts the specimen using a surface to surface contact without friction, see Figure 3, as the contact takes place only along a line at the top of the specimen and frictionless contact would be the most conservative since the specimen's movement is kept unconstrained. The displacements of the nodes in contact with the rolling beds are constrained in the z-direction. Additional constraints on two nodes, also in contact with the rolling beds and at half the length, are applied to prevent rigid body motions along the $\mathrm{x}$ - and $\mathrm{y}$-directions and rotation in the $\mathrm{x}-\mathrm{y}$ plane. The load case is solved as a static load case using large deformations. During the analysis the failure indices are calculated using the UVARM subroutine.

\section{Results}

\subsection{Experimental results}

In nine of the specimens, failure initiation was observed at a distance from the centreline in a mode similar to the transverse interbundle failure as shown in Figure 4 (c). The offset from the centreline is explained by the applied loading at the centre top of the specimens, which creates a compressive contact stress in this region and therefore decreases the magnitude of the tensile out-of-plane stresses in the radius. The location 
of the crack is approximately half-way through the thickness of the specimen. The observed failure initiation is unstable and a single crack is formed through the length of the specimen. One of the $[90 / 0]_{4 s}$ specimens failed simultaneously at multiple locations through the thickness, however no difference could be seen in the mechanical response. 

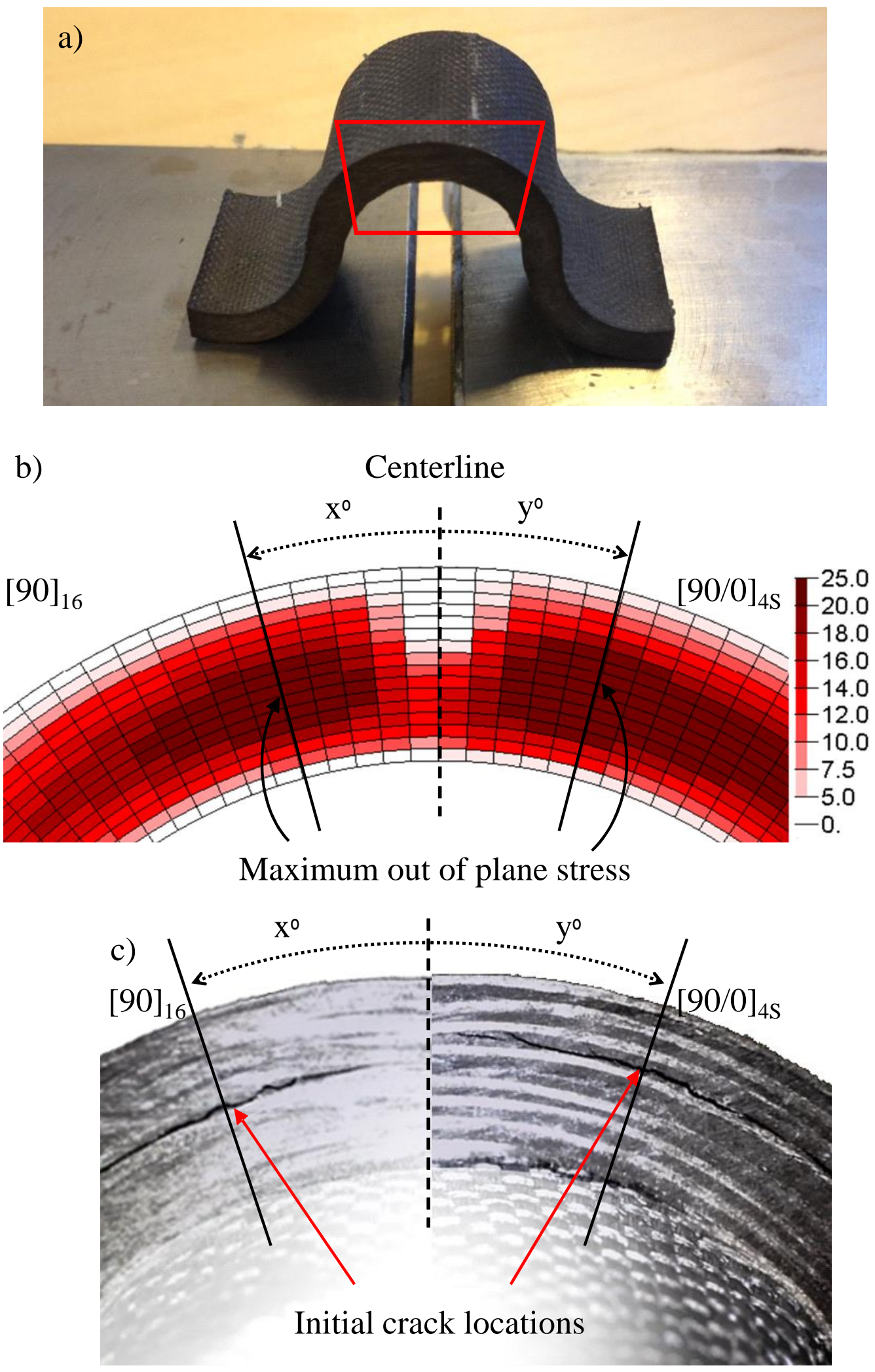

Figure 4. Detailed study of first visible failure location. a) Front view of test specimen. b) Left: [90] $]_{16}$ Out-of-plane stress distribution when $\sigma_{33, \max }=25 \mathrm{MPa}$. Right: [90/0 $]_{4 \mathrm{~S}}$ Out-of-plane stress distribution when $\sigma_{33, \max }=25 \mathrm{MPa}$. c) Left: $[90]_{16}$ lay-up. Photo from experimental test at first ply failure. Right: $[90 / 0]_{4 S}$ lay-up. Photo from experimental test at first ply failure. 
For both lay-ups, $[90]_{16}$ and $[90 / 0]_{4 S}$, the three specimens that were continuously loaded after failure initiation showed the same failure sequence. The specimens failed by the formation and growth of a crack centrally through the thickness. The crack grew to a length of approximately $5 \mathrm{~mm}$ in the tangential direction, see Figure 4 (c).

For the $[90]_{16}$ lay-up the maximum load was $1417 \mathrm{~N}($ standard deviation $=38 \mathrm{~N})$ at failure initiation with an average displacement of $0.60 \mathrm{~mm}$ (standard deviation $=0.04 \mathrm{~mm}$ ), see Figure 5 and Table 3 . The first crack for this lay-up initiated at about 20 degrees from the centre line at the middle through the thickness, see Figure 4 (c).
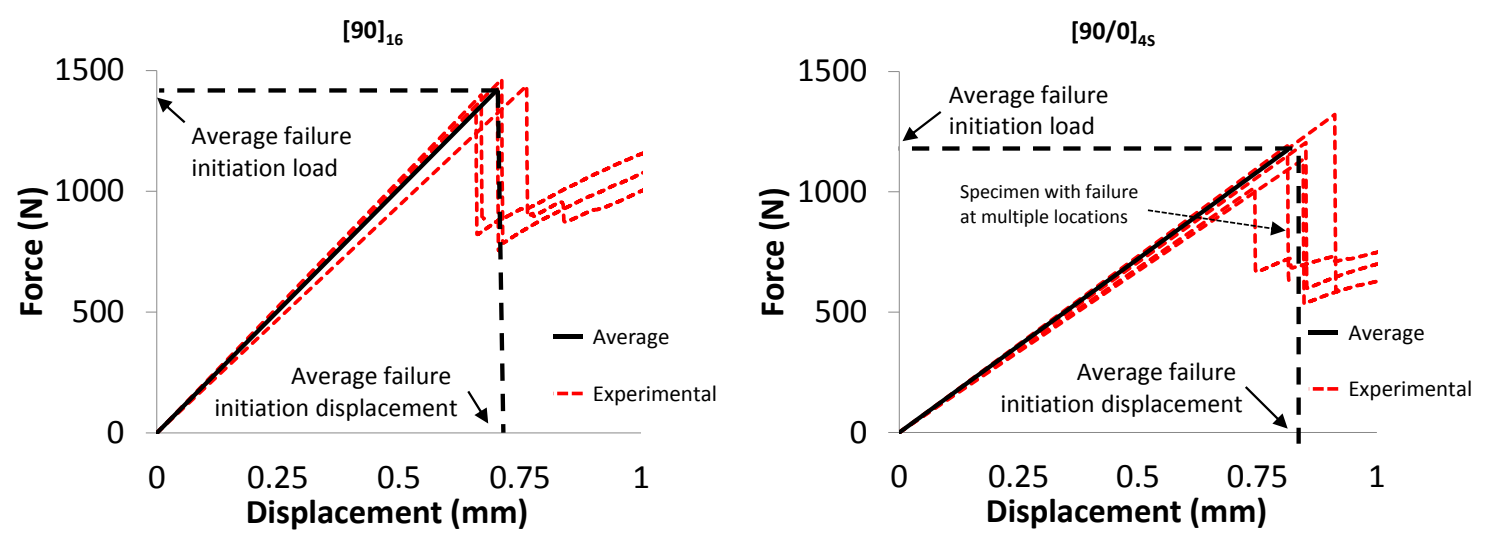

Figure 5. Load versus displacement curves. Left: [90 $]_{16}$ lay-up. Right: [90/0 $]_{4 \mathrm{~S}}$ lay-up.

\begin{tabular}{lcc}
\hline$[90]_{16}$ & Load experiment $(\mathrm{N})$ & Disp. experiment $(\mathrm{mm})$ \\
\hline Average & 1417 & 0.60 \\
St.dev. & 38 & 0.04 \\
\hline & \\
\hline$[90 / 0]_{4 \mathrm{~S}}{ }^{\mathrm{a})}$ & Load experiment $(\mathrm{N})$ & Disp. experiment $(\mathrm{mm})$ \\
\hline Average & 1174 & 0.67 \\
St.dev. & 111 & 0.10 \\
\multicolumn{3}{l}{} \\
a) One specimen failed at multiple locations without affecting the mean data for the applied \\
loads and displacements at failure initiation.
\end{tabular}

Table 3: Average and standard deviation of the loads and displacements at failure initiation. Five specimens were tested for each lay-up. 
For the $[90 / 0]_{4 \mathrm{~S}}$ lay-up the maximum load was $1174 \mathrm{~N}$ (standard deviation $=111 \mathrm{~N}$ ) at failure initiation with an average displacement of $0.67 \mathrm{~mm}$ (standard deviation $=0.1 \mathrm{~mm}$ ), see Figure 5 and Table 3 . For this lay-up, the resulting crack is often located at the interface between a $90^{\circ}$ and $0^{\circ}$ ply and often migrates to the other interface of the $0^{\circ}$ ply, as shown in Figure 4 (c).

\subsection{Numerical simulations}

The numerical model is used to predict failure initiation using the failure criteria described above. The out-of-plane stress distributions in the radial direction for the two lay-ups, $[90]_{16}$ and $[90 / 0]_{4 S}$, are illustrated in Figure 4 (b). It is clear that the out-ofplane stresses are higher at about 20 degrees from the centreline. The predicted failure location correlates well with the experimental results shown in Figure 4 (c). For the [90/0 $]_{4 S}$ lay-up, a slightly larger area is stressed in both the tangential and radial directions compared to the [90]16 lay-up.

The $[90]_{16}$ lay-up was chosen to suppress transverse intrabundle failure since all fibres are placed along the curvature of the specimen. This lay-up will make the failure in the out-of-plane direction dominant, i.e. higher failure index for the interbundle failure mode compared to the intrabundle failure mode. This can be seen in Figure 6 where the corresponding failure indices for both modes are presented.

The location of the maximum failure index for the two different modes are similar, as illustrated in the contour plots in Figure 6. The failure is located to the sides of the centreline, approximately half way through the thickness. The 
transverse interbundle failure is governed by the high tensile out-of-plane stresses, $F I_{\mathrm{M}, \mathrm{MI}}=1$ in Figure 6 (left), with a fracture plane at $90^{\circ}$. The transverse intrabundle failure index, $F I_{\mathrm{M}, \mathrm{B}}=0.20$ in Figure 6 (right), corresponding to a fracture plane at $90^{\circ}$, is also dominated by the high tensile out-of-plane stresses. The difference in the predicted failure indices can be attributed to the lower outof-plane strength used in the proposed interbundle failure criterion.

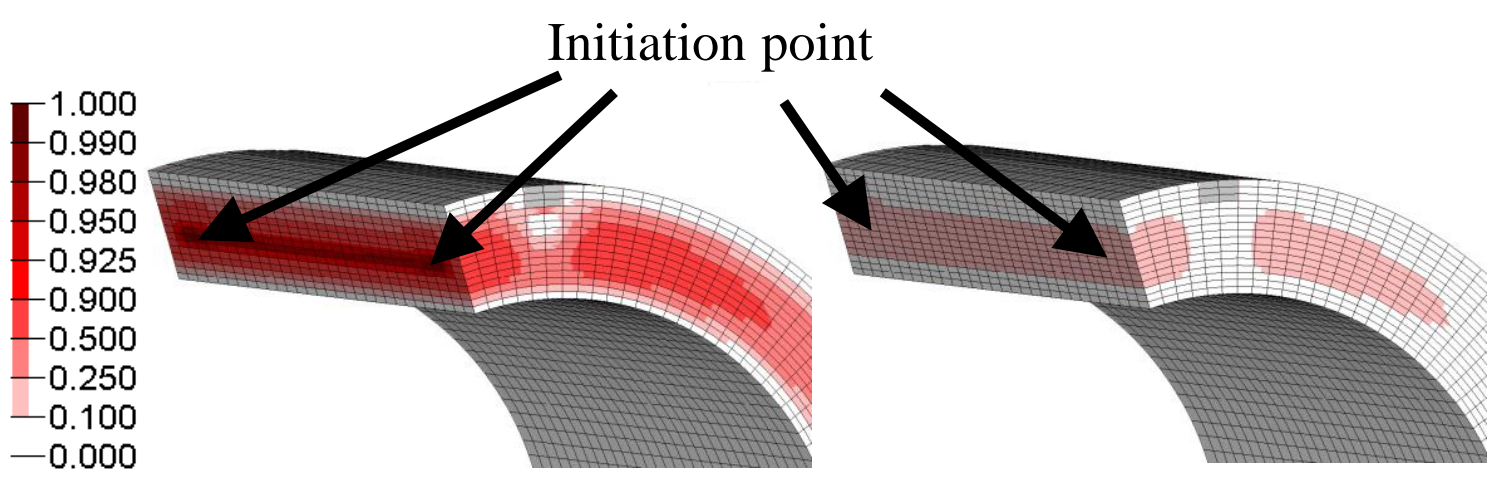

Figure 6. Failure indices for transverse interbundle failure (left) and transverse intrabundle failure (right) for the $[90]_{16}$ lay-up. The transverse intrabundle failure criterion is identical to the LaRC05 failure criterion for transverse matrix related failure.

In the $[90 / 0]_{4 S}$ lay-up, the interbundle failure is also governed by the out-of-plane stress as for the [90 $]_{16}$ lay-up. The failure indices for both failure modes are shown in Figure 7. The transverse interbundle failure, $F I_{\mathrm{M}, \mathrm{MI}}=1$ in Figure 7 (left), still initiates at a location to the side of the centreline, with a fracture plane at $90^{\circ}$. The intrabundle failure, $F I_{\mathrm{M}, \mathrm{B}}=0.30$ in Figure 7 (right), is in this case controlled by high transverse tensile in-plane stresses in the second innermost ply at the centre of the specimen with a fracture plane at $15^{\circ}$. The influence of compressive loads and shear between the plies with different orientation results in an angle slightly different from $0^{\circ}$. 


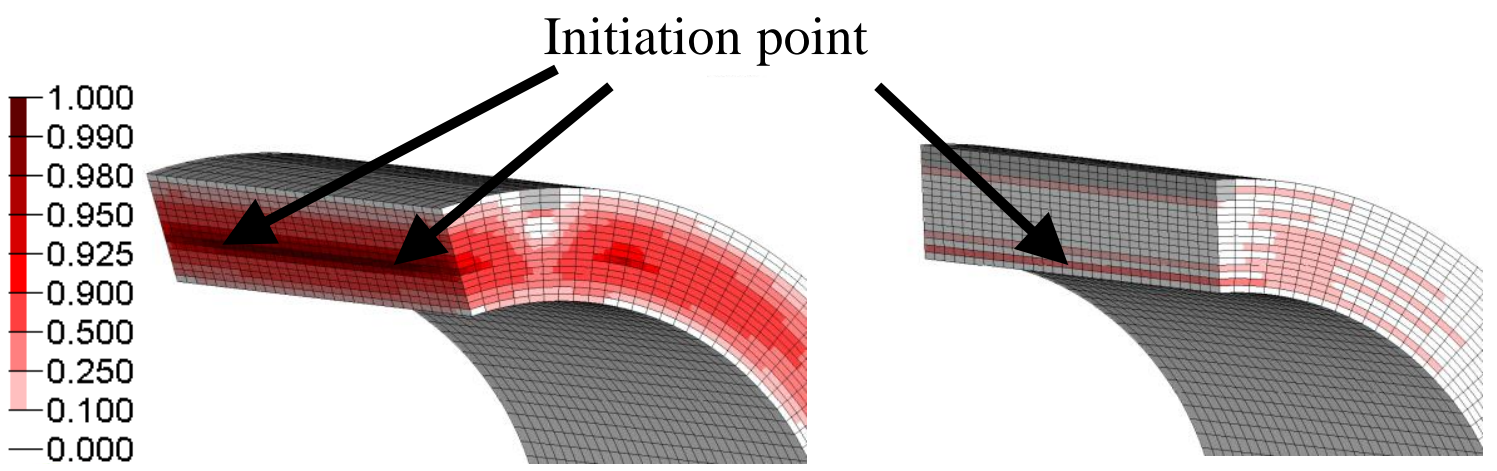

Figure 7. Failure indices for transverse interbundle failure (left) and transverse intrabundle failure (right) for the $[90 / 0]_{4 \mathrm{~S}}$ lay-up. The transverse intrabundle failure criterion is identical to the LaRC05 failure criterion for transverse matrix related failure.

\subsection{Failure load predictions}

The estimated failure load using the numerical model is considerably lower compared to the experimental data. This difference can arise from the definition of the failure load at initiation from the experiments. This load is defined as the first load drop together with live observation using a microscope and unassisted sound emission, which sets an upper limit for the failure initiation. Different factors that may influence the predicted failure load have been studied and are summarised in Table 4. These include variation of out-of-plane strength, $Z_{\mathrm{T}}, Z_{\mathrm{T}, \min }, Z_{\mathrm{T} \text {,max }}$, the consideration of a non-linear effect, $Z_{\mathrm{T}, \mathrm{NL}}$, and the consideration of the secant stiffness of the material, $Z_{\mathrm{T}, E 33=6.4 \mathrm{GPa}}$.

\begin{tabular}{cc}
\hline$[90]_{16}$ & Predicted Load experiment $(\mathrm{N})$ \\
\hline$Z_{\mathrm{T}}=14.7 \mathrm{MPa}$ & $661 \mathrm{~N}$ \\
$Z_{\mathrm{T}, \min }=13.0 \mathrm{MPa}$ & $593 \mathrm{~N}$ \\
$Z_{\mathrm{T}, \max }=16.4 \mathrm{MPa}$ & $729 \mathrm{~N}$ \\
$Z_{\mathrm{T}, \mathrm{NL}}=18.0 \mathrm{MPa}$ & $781 \mathrm{~N}$ \\
$Z_{\mathrm{T}, E 33=6.4 \mathrm{GPa}}=14.7 \mathrm{MPa}$ & $691 \mathrm{~N}$ \\
\hline
\end{tabular}

Table 4: Predicted failure load with different out-of-plane strength values based on variations of the material data in Ref. [5].

\subsubsection{Sensitivity to out-of-plane strength}

The failure prediction is sensitive to the out-of-plane strength. The out-of-plane stress distribution in the specimens is such that a difference of $3.4 \mathrm{MPa}$ in $Z_{\mathrm{T}}$, (i.e. 
$Z_{\mathrm{T}, \max }-Z_{\mathrm{T} \text {,min }}$ as presented in Table 4 ), which corresponds to the scatter measured in Ref. [5], results in a variation in the predicted failure load of approximately $140 \mathrm{~N}$.

\subsubsection{Non-linear material behaviour}

The material shows a non-linear stress-strain behaviour in the out-of-plane direction. The nominal failure stress is $Z_{\mathrm{T}}=14.7 \mathrm{MPa}$ and the strain to failure is $0.23 \%$ [5]. The present FE-model considers a linear material behaviour and to compensate for this, two models are evaluated. One with a failure stress $Z_{\mathrm{T}, \mathrm{NL}}$ of $18.0 \mathrm{MPa}$, determined from the out-of-plane stiffness and strain to failure. The other one uses a softer model in the outof-plane direction, with $E_{33}$ equal to $6.4 \mathrm{GPa}$, determined from the out-of-plane strength and strain to failure (secant modulus). The first model predicts a failure load of $781 \mathrm{~N}$ and the second model predicts a failure load of $691 \mathrm{~N}$, as reported in Table 4.

\subsubsection{Volume effect}

In Wisnom [20], the size effect on strength is discussed based on the weakest-link principle. Assuming that the defects are randomly distributed within the material, a larger volume thereby has a larger probability to contain a larger defect that would be

critical. The geometry between the specimens is different, with 187 plies for the out-ofplane tensile specimen [5] and 16 plies for the corrugated specimens. This results in different stress distributions between the specimen types. Using the approach described in Ref. [20] for the out-of-plane strength the dependence of the volume being loaded can be analysed. The corrugated specimen is denoted as 1 and the out-of-plane tensile specimen as 2 . 
Estimating the Weibull modulus according to Eq. (7) [20], based on the coefficient of variance for the material data in Ref. [5], gives:

$$
m \cong 1.2 / c v=1.2 / 0.095=12.6
$$

Since the corrugated specimen does not have a constant stress distribution, the calculation is done based on volume as a function of the size of the stressed region. The volume, $V_{1}$, of the most highly stressed region is calculated with a square of length $l$ in the 2-3-plane that spans through the length of the specimen, as shown in Figure 8. As the stress along the length also varies, the results for a small volume, corresponding to a cube of side $l$, are also presented. The volume of the tensile specimen, $V_{2}$, is taken as the test section, $12.5 \times 7.5 \times 9 \mathrm{~mm}^{3}$.
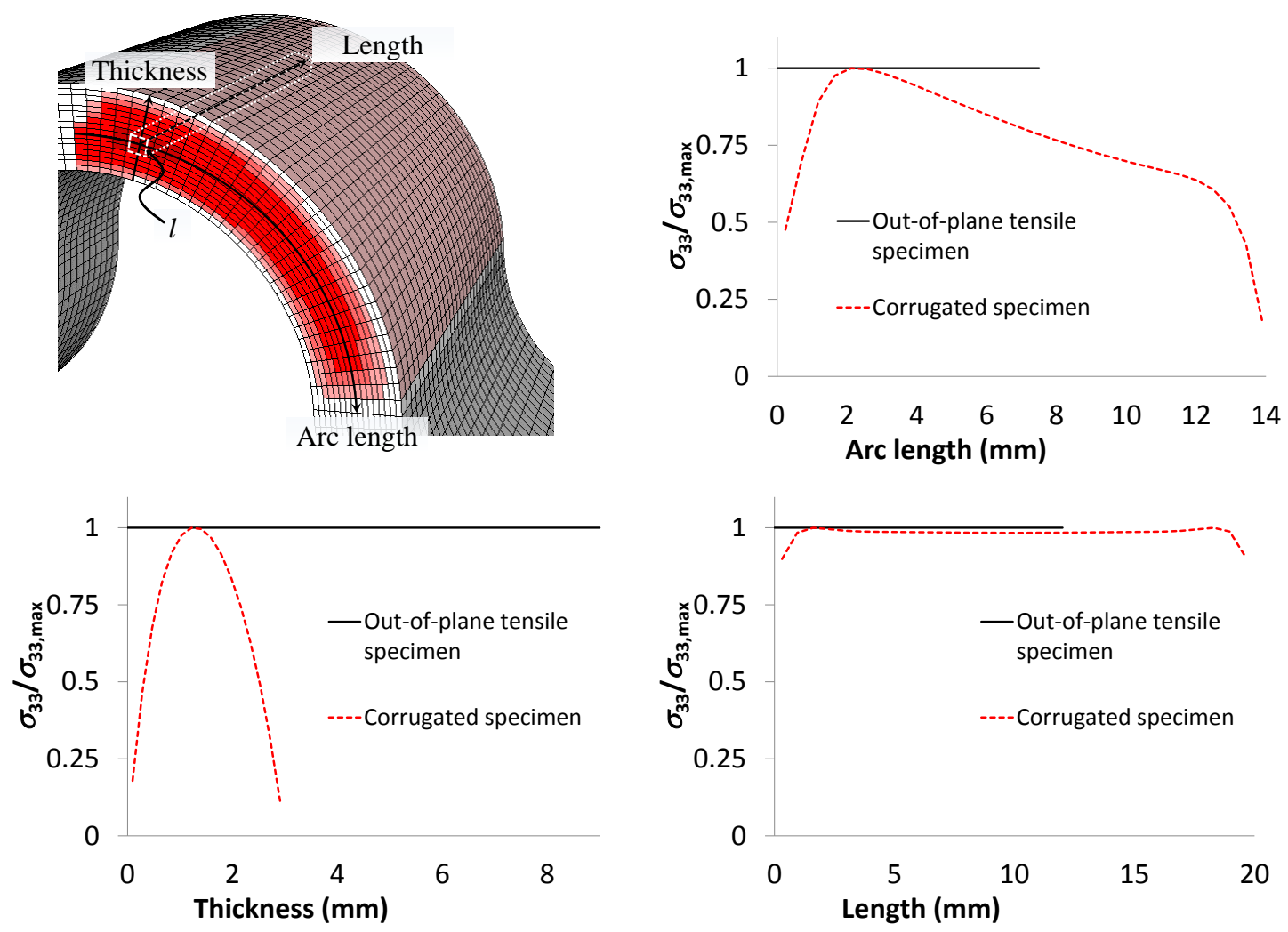

Figure 8. Normalised out-of-plane stress distribution $\left(\sigma_{33} / \sigma_{33, \max }\right)$ along the two specimens. Top left: Different paths. Top right: Stress distribution along the fibre direction. Bottom left: Stress distribution in the thickness direction. Bottom right: Stress distribution in the length direction. 
The size effect can be calculated according to Eq. (8) [20]:

$$
\frac{s_{1}}{s_{2}}=\left[\frac{V_{1}}{V_{2}}\right]^{\left(\frac{-1}{m}\right)}
$$

where $s_{1}$ is the stress in the corrugated specimen and $s_{2}$ is the stress in the out-of-plane tensile specimen.

The apparent out-of-plane strength as a function of length 1 is shown in Figure 9 (a). It is clear that the small area that is stressed according to Figure 8 would result in a clear size effect of the out-of-plane strength.

(a)

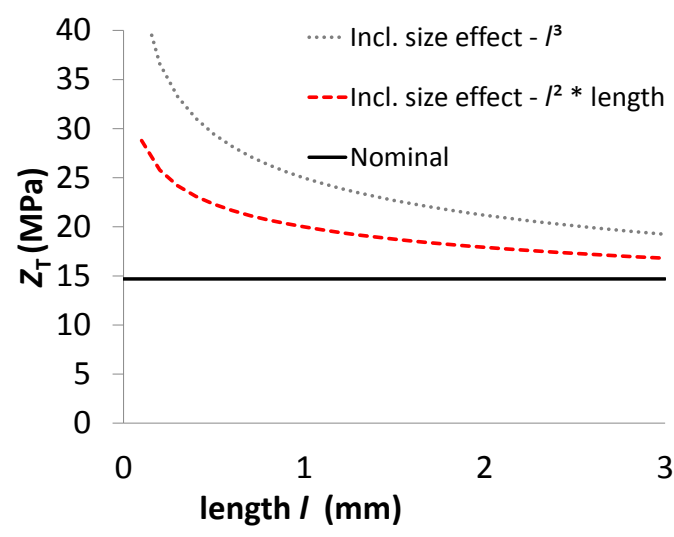

(b)

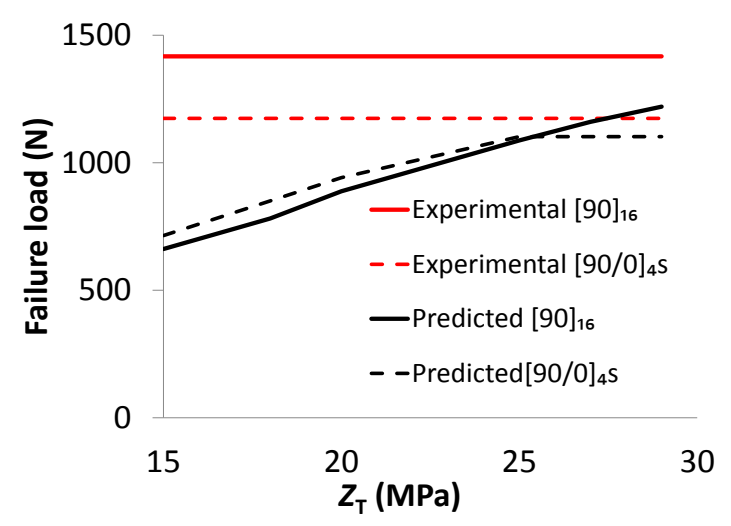

Figure 9. a) Apparent $Z_{\mathrm{T}}$ strength as a function of the stressed volume based on a rectangle with cross section $l \times l$ through the stressed length of the corrugated specimen and a box with side $l$. b) Predicted failure load versus out-of-plane strength (solid lines for the [90] $]_{16}$ lay-up and dashed lines for the [90/0 $]_{4 \mathrm{~s}}$ lay-up).

The predicted failure loads using the implemented failure criteria for different out-ofplane strength values from the estimated apparent strength are presented in Figure 9 (b) for both lay-ups. Increasing the out-of-plane strength clearly results in an increase in the failure load. For the $[90 / 0]_{4 \mathrm{~S}}$ there is a change in failure mode when $Z_{\mathrm{T}}$ equals $25 \mathrm{MPa}$ from interbundle to intrabundle failure. The intrabundle failure predicted by the transverse criterion in LaRC05 for the [90/0 $]_{4 \mathrm{~S}}$ layup would be due to high in-plane 
stresses in combination with shear between the plies when bending the UD-specimen. Delamination might occur prior to intrabundle failure as delamination is not included in the LaRC05-criteria.

\subsubsection{Design of specimen}

The thick double waisted specimens used by Bru et al. [5] are studied by Ferguson et al. [21] where it is found that the failure occurs at the beginning of the radius. In this study, the stress concentration at this location would be at least 1.15 compared to the middle section of the specimen. This factor does not include the effects from either machining of the specimens or effects from the combi-yarn within the material. From Ref. [5] the failure is shown at a plane close to the critical location from the FE analysis in Ref. [21] and where a combi-yarn is located. So this would probably result in a lower value of the out-of-plane strength of the material.

The failure load from the [90 $]_{16}$ lay-up show a variation of 2.5 percent compared to the variation in failure load from Ref. [5] that was as large as 14 percent. This indicates that the thick out-of-plane tensile specimen could include more defects than the thinner corrugated specimens. This may have contributed to a reduced out-of-plane strength in Ref. [5], as discussed.

\section{Discussions}

The transverse interbundle failure in NCF reinforced composites is critical under certain stress conditions. With the proposed failure criteria it is possible to identify and accurately predict this mode of failure initiation. Predictions are, as always, sensitive to the data provided, and the out-of-plane strength is a material parameter that is hard to 
measure. This makes predictions of failure load difficult. Both location and failure mode can differ significantly from predictions made with failure criteria that are based on the assumption of transverse isotropy. This can be seen for the [90/0 $]_{4 \mathrm{~S}}$ lay-up where the failure index according to transverse isotropy, $F I_{\mathrm{M}, \mathrm{B}}$, is only 0.3 while the failure index for the transverse interbundle failure, $F I_{\mathrm{M}, \mathrm{MI}}$, equals 1.0. For this lay-up, failure initiation is predicted at different locations for the two different failure modes.

The critical failure mode for the [90/0 $]_{4 s}$ lay-up depends on the relationship between the transverse in-plane strength and the transverse out-of-plane strength. If in-situ strength is not accounted for, the lower in-plane strength values could give the intrabundle failure as the critical mode. Using in-situ strength values, the transverse inplane strength increases and the interbundle failure becomes the critical mode, as observed in the experiments.

The difference in failure load between experiments and numerical simulations cannot be explained by the scatter in material data nor by the neglect of non-linear effects in the numerical model. The observed failure initiation, identified by the first load drop, live observation with a use of microscope and unassisted sound emission, sets an upper limit for the failure initiation. Micro-cracks, inside the specimen, could have evolved prior to this, as these might not result in a significant change of stiffness nor be detected without acoustic emission, but subsequently results in the unstable crack growth. 
For composite materials the relevance of the measured material data for the specific design is important. Aspects that may influence the strength, other than the volume effect, such as meso structure variations due to manufacturing parameters and size effects for the textile are discussed below.

For NCF reinforced composites the meso structure depends on the manufacturing conditions for both the reinforcing fabric and the composite. The specimens used in this study and the specimens studied by Bru et al. [5] were manufactured using vacuum infusion under identical curing and post curing conditions. However there is a difference in meso structure. The meso structure from the out-of-plane tensile specimen shows larger discontinuities at the stitching yarns as shown in Figure 10. In Ref. [6], the effects of perturbations on fibre bundle geometry is investigated and demonstrate a strong influence on the out-of-plane strength. The difference in meso structure is likely dependent on the pressure distribution during infusion and curing of the very thick laminate for characterisation, about $35 \mathrm{~mm}$ thick.

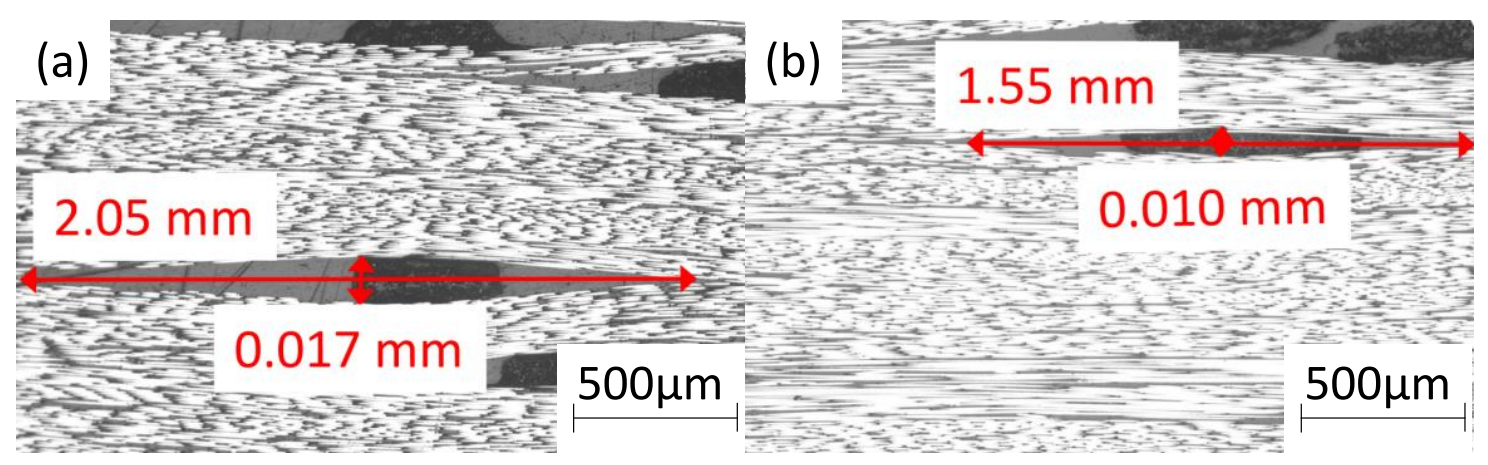

Figure 10. Micrographs showing the stitching yarns and resin rich areas nearby. a) Meso structure for the material used for out-of-plane tensile testing. b) Material similar to the one used for the corrugated specimens.

As shown in Figure 10, the stitching yarn and the surrounding matrix material, referred to as fish eyes by Schneider [22], create islands approximately $2 \mathrm{~mm}$ long for 
the out-of-plane tensile specimen and approximately $1.5 \mathrm{~mm}$ long for the corrugated specimens. The local stress concentration are therefore different in both specimens which implicitly means that the strength of the material is also different in both specimens.

As there is a competition between the interbundle failure and the intrabundle failure for out-of-plane loading it is important to first have measurements of the out-of-plane strength that is representative for the specimen i.e. similar size and manufacturing process. Then the specimens need to be designed with lay-ups where it is possible to distinguish which failure mode had actually initiated the failure. A curved specimen similar to the one used by Charrier et al. [23] could be advantageous as the out-of-plane stress will be more homogenous compared to the corrugated design used in this work. Such a design and set up would also make it easier to use digital image correlation to monitor the displacement and strain field.

\section{Conclusions}

NCF reinforced composites are not transversely isotropic and traditional failure criteria for UD composites cannot be used to capture all existing failure modes. To allow robust and efficient design with NCF reinforced composites a set of failure criteria that considers the orthotropic behaviour is presented and used in the current study. The failure criteria operate at the ply level and are implemented into a commercial FE package. 
Results from numerical simulations of two different lay-ups show that the additional failure mode, interbundle failure, is a critical mode under certain stress configurations. This is a mode that traditional failure criteria, based on the assumption of transverse isotropy, cannot predict.

The numerical simulations are validated against experimental data from tests performed on corrugated specimens loaded with an opening moment. All the tested specimens failed by the predicted failure mode in the numerical analyses.

As the out-of-plane strength property is hard to measure, it is important to establish a method to measure this property that is relevant for the current design. It is proposed to measure out-of-plane strength on L-shaped specimens as Charrier et al. [23] have done for UD-specimens.

The implemented model accurately predicts failure mode and location for transverse matrix related failure initiation. Failure loads are however underestimated and found inherent to unrepresentative material data. That is the strength data were measured on too large material volumes. Consequently, there is a need for further research to establish representative material data before such method can be used for efficient design of NCF reinforced composite structures subjected to complex three-dimensional stress states. 


\section{Acknowledgements}

The work was partly funded through Volvo Car Industrial PhD program (VIPP) and the Swedish Research Council (VR) 2012-4320. In addition, financial support from VINNOVA, via LIGHTer SRA1 Modelling, is gratefully acknowledged.

Andreas Flood and Johan Schenström at the Material centre at Volvo Car

Corporation are acknowledged for their support with performing the physical testing.

\section{References}

[1] Dry Composites. BMW i3: first mass produced composite car in production n.d. http://www.drycomposites.com/bmw-i3-first-mass-producedcomposite(accessed May 20, 2015).

[2] Mårtensson P, Zenkert D, Åkermo M. Method for the cost-efficient and weightefficient material diversity and partitioning of a carbon fibre composite body structure. Proceedings of the Institution of Mechanical Engineers Part D: Journal of Automobile Engineering, 2015. doi:10.1177/0954407015578037

[3] Molker H, Gutkin R, Oldenbo M, Asp LE. Efficient sizing methods for composites primary structures in automotive applications. In: Proceedings of ECCM16 - 16th European conference on composite materials, Seville, Spain, June, 2014. doi: 10.13140/2.1.1994.1120

[4] Olsson R. Experimental observations on the orthotropic transverse strength of Non-Crimp Fabrics composites. Swerea Sicomp TN15006, Piteå, Sweden: 2015.

[5] Bru T, Hellström P, Gutkin R, Ramantani D, Peterson G. Characterisation of the mechanical and fracture properties of a uni-weave carbon fibre/epoxy non-crimp 
fabric composite. Data in Brief, 2016;6:680-695.

[6] Molker H, Wilhelmsson D, Gutkin R, Asp LE. Orthotropic criteria for transverse failure of non-crimp fabric reinforced composites. Journal of Composite Materials, 2016;50(18):2445-2458

[7] Paul PC, Saff CR, Sanger KB, Mahler MA, Kan HP, Kautz EF. Out of plane analysis for composite structures. NASA Conference paper 19920023283, 1990.

[8] Puck A, Schürmann H. Failure analysis of FRP laminates by means of physically based phenomenological models. Composite Science and Technology, 2002;62:1633-1662.

[9] Pinho S, Darvizeh R, Robinson P, Schuecker C, Camanho PP. Material and structural response of polymer-matrix fibre-reinforced composites. Journal of Composite Materials, 2012;46:2313-41.

[10] Kaddour AS, Hinton MJ. Maturity of 3D failure criteria for fibre-reinforced composites: Comparison between theories and experiments: Part B of WWFE-II. Journal of Composite Materials, 2013;47(6-7):925-66.

[11] Pinho S, Dávila CG, Camanho PP, Iannucci L, Robinson P. Failure models and criteria for FRP under in-Plane or three-dimensional stress states including shear non-linearity. NASA-TM-2005213530, 2005.

[12] Catalanotti G, Camanho PP, Marques AT. Three-dimensional failure criteria for fiber-reinforced laminates. Composite Structures, 2013;95:63-79.

[13] Ye L. Role of matrix resin in delamination onset and growth in composite laminates. Composites Science and Technology, 1988;33:257-77.

[14] Asp LE. Local models for NCF composite materials mechanical performance prediction. 16th International Conference on Composite Materials, 2007 
[15] Juhasz J, Rolfes R, Rohwer K. A new strength model for application of a physically based failure criterion to orthogonal 3D fiber reinforced plastics. Composite Science and Technology 2001;61:1821-32

[16] Dassault Systèmes. ABAQUS Documentation. 6.14 ed. Providence, RI, USA: 2014.

[17] Camanho PP, Dávila CG, Pinho ST, Iannucci L, Robinson P. Prediction of in situ strengths and matrix cracking in composites under transverse tension and inplane shear. Composites: Part A, 2006;37(2):165-76.

[18] Grauers L, Olsson R, Gutkin R. Energy absorption and damage mechanisms in progressive crushing of corrugated NCF laminates: Fractographic analysis. Composite Structures, 2014;110:110-117. doi:10.1016/j.compstruct.2013.11.001

[19] Martin RH. Delamination failure in a unidirectional curved composite laminate. Nasa Technical Report, NASA-CR-182018, 1990.

[20] Wisnom MR, Size effects in the testing of fibre-composite materials. Composite Science and Technology, 1999;59:1937-57. doi:10.1016/S0266-3538(99)00053-6

[21] Fergusson RF, Hinton MJ, Hiley MJ, Determining the through-thickness properties of FRP materials. Composites Science and Technology, 1998;58:141120.

[22] Schneider M. Automated analysis of defects in non-crimp fabrics for composites. In: Lomov SV, editor. Non-crimp fabric Composites. Cambridge: Woodhead Publishing Limited, 2011. p.103-114.

[23] Charrier JS, Laurin F, Carrere N, Mahdi S, Determination of the out-of-plane tensile strength using four-point bending tests on laminated L-angle specimens with different stacking sequences and total thicknesses. Composites: Part A, 
Henrik Molker, Renaud Gutkin, Leif E. Asp

2016;81:243-53. doi:10.1016/j.compositesa.2015.11.018 